\title{
Vulnerability assessment of areas affected by Chinese cryospheric changes in future climate change scenarios
}

\author{
HE Yong $^{1 *}$, WU YongFeng ${ }^{2} \&$ LIU QiuFeng ${ }^{1}$ \\ ${ }^{1}$ National Climate Center, Beijing 100081, China; \\ ${ }^{2}$ Institute of Environment and Sustainable Development for Agriculture, Chinese Academy of Agricultural Science, Beijing 100081, China
}

Received July 25, 2012; accepted September 20, 2012

\begin{abstract}
Using the definition of vulnerability provided by the Intergovernmental Panel on Climate Change, this paper assesses the vulnerability of areas affected by Chinese cryospheric changes from 2001 to 2020 and from 2001 to 2050 in A1 and B1scenarios. Seven indices are used in the vulnerability assessment: glacial area fraction, interannual variability of permafrost depth, interannual variability of surface snow area fraction, interannual variability of surface runoff, interannual variability of surface temperature, interannual variability of vegetation growth, and interannual variability of the human development index. Assessment results show that the overall vulnerability of the studied areas in China increases from east to west. The areas in the middle and eastern parts of China are less vulnerable compared with western parts and parts of the Tibetan Plateau. The highest vulnerability values are found from 1981 to 2000, and the least ones are found from 2001 to 2050. The vulnerable areas increase from the period of 1981 to 2000 to the period of 2001 to 2050 , and the less vulnerable areas decrease. The highly vulnerable areas increase from the period of 1981 to 2000 to the period of 2001 to 2020 and then decrease from the period of 2001 to 2020 to the period of 2001 to 2050 . This decrease in vulnerability is attributed to the decrease in exposure and sensitivity to Chinese cryospheric changes along with a concomitant increase in adaptation.
\end{abstract}

cryospheric change, vulnerability assessment, exposure, sensitivity, adaptation

Citation: He Y, Wu Y F, Liu Q F. Vulnerability assessment of areas affected by Chinese cryospheric changes in future climate change scenarios. Chin Sci Bull, 2012, 57: 4784-4790, doi: 10.1007/s11434-012-5525-0

Cryosphere is an essential component of the earth's climate system, significantly affects natural and human systems. As research in global change progresses, cryospheric change has become not only a dynamic element of climate system research but also a main concern in global change and sustainable development [1-8]. Chinese cryospheric distribution is the most extensive in medium and low latitude areas. Cryospheric changes bring about not only drought and flood on the Yangzi River Valley [9], depleted water resources in west arid areas [10], and variation of vegetation on the Tibetan Plateau [11-13] at the regional level but also sea level rises globally [14]. Because of global warming, $82 \%$ of glaciers in China have shrunk or disappeared, and their areas have decreased from $18 \%$ to $2 \%$ [15-17]. The Tibetan Plat-

*Corresponding author (email: heyong@ cma.gov.cn) eau's permafrost has noticeably been degraded. The decrease in seasonal frozen depth is most significant in the middle and northeastern regions of the Tibetan Plateau, thinning from $8 \%$ to $10 \%$ [18]. The snow cover in Tibet shows an increasing trend, with the annual snow depth increasing by $2.3 \%$ from 1957 to 1998 . The glacial area on the Tarim Valley will shrink about $2 \%$ to $4 \%$ in the next 50 years [19]. The permafrost area of the Tibetan Plateau will also decrease from $8.8 \%$ to $13.5 \%$ [20], and the active layer thickness of $0.5 \mathrm{~m}$ to $1.5 \mathrm{~m}$ will increase to $1.5 \mathrm{~m}$ to $2.0 \mathrm{~m}$ [21]. The snow cover in Tibet [22] and the snow depth in Xinjiang [23] will likewise decrease. Chinese cryospheric changes in the future will significantly affect not only the safety of the ecosystem and the environment but also the sustainability of water resources in west China.

Vulnerability is the degree to which a system is suscepti- 
ble to and unable to cope with the adverse effects of climate change, including climate variability and extremes. Vulnerability, which is a function of the character, magnitude, and rate of climate change, refers to the variation to which a system is exposed, its sensitivity, and its adaptive capacity [24]. Vulnerability assessment aims to predict and assess a system's response to outer exposure, its capacity to recover, and the resistance needed to maintain the stability of the system. Appropriate intervention policies are also explored to avoid the further degradation of the system and to decrease its vulnerability. The vulnerability of cryospheric changes refers to the degree of effects brought on natural and human systems as a result of changes in glacier, permafrost, and snow, including the oasis system in arid regions and ecosystems and human society in cold regions. The vulnerability assessment of cryospheric changes involves an evaluation of the vulnerability of natural and human systems caused by present and future cryospheric changes. To date, the vulnerability assessment of cryospheric changes is a relatively new research field. Therefore, its indices and approaches have yet to be improved [25-27]. Using the definition of vulnerability provided by the Intergovernmental Panel on Climate Change (IPCC), this paper conducts a quantitative vulnerability assessment of Chinese cryospheric changes for the next 50 years. The effects of these changes on natural and human systems are also analyzed, which will be useful in strategic policy making for environmental protection and adaptation to climate change.

\section{Research area, methods and data}

\subsection{Research area}

The area affected by Chinese cryospheric changes (unpublished work) is distributed over 1173 counties in 21 provinces of Northwestern China, Northern China, Northeastern China, Eastern China, and the middle and western parts of Southwestern China. The entire area spans 7.494 million $\mathrm{km}^{2}$ (see colored areas in Figures 1 and 2).

\subsection{Method and index}

(1) Research method. Based on the definition provided by the IPCC, Formula (1) for vulnerability assessment is established. $F$ is the vulnerability, $i$ is the ordinal number of the
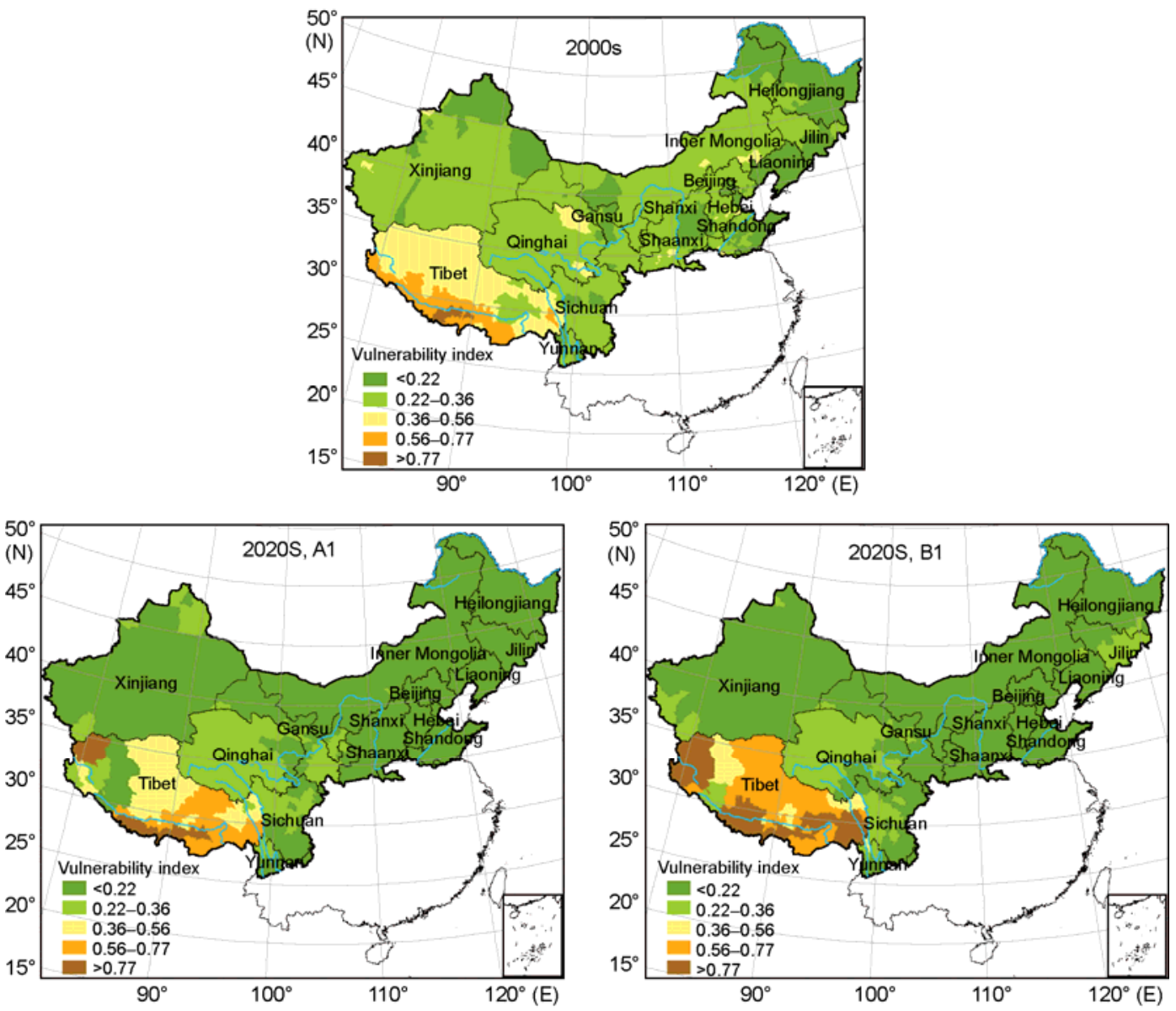

Figure 1 Vulnerability distribution of Chinese cryospheric changes in the 2000s and 2020s. Xinjiang: Xinjiang Uygur Autonomous Region; Tibet: Tibet Autonomous Region (the same below). 

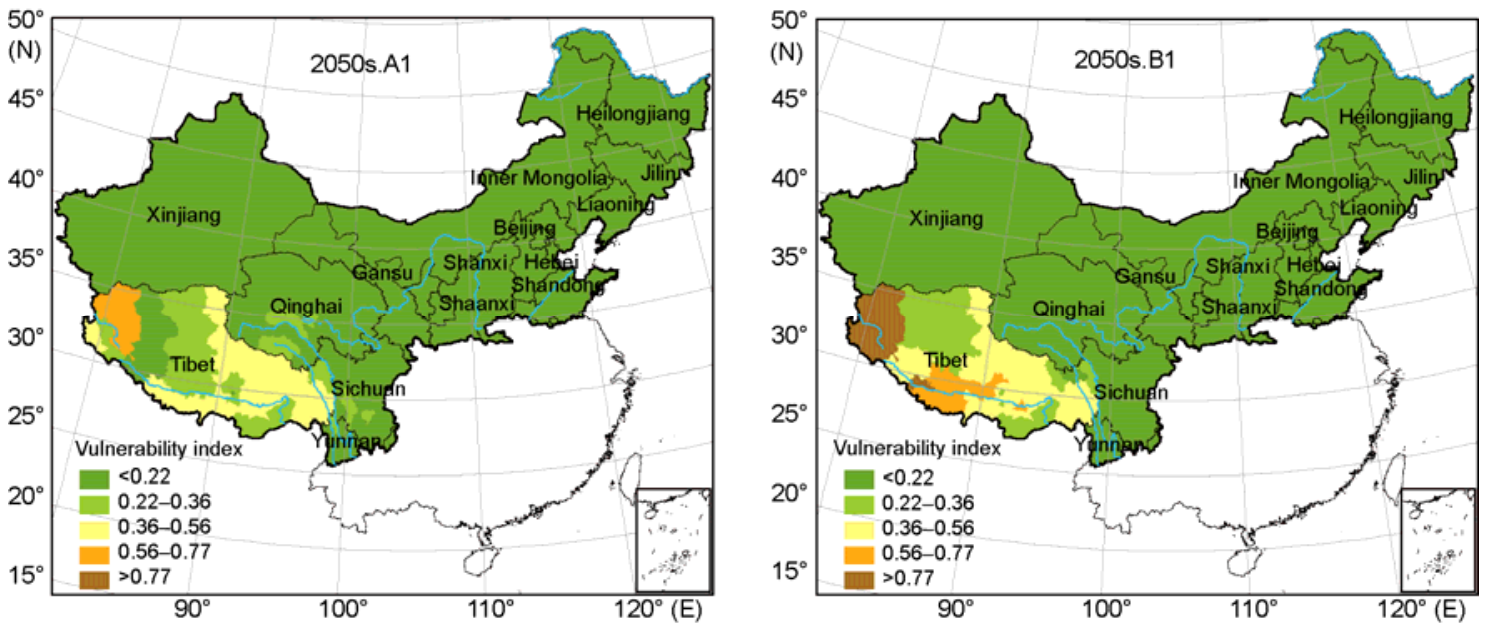

Figure 2 Vulnerability distribution of Chinese cryospheric changes in the 2050s.

index, $l$ is the number of exposure index, $m$ is the number of sensitivity index, $n$ is the number of adaptation index, $W_{\mathrm{ei}}$ is the weight of the $i$ th exposure index, $W_{\mathrm{si}}$ is the weight of the $i$ th sensitivity index, $W_{\text {ai }}$ is the weight of the $i$ th adaptation index, $E_{i}$ is the $i$ th exposure index, $S_{i}$ is the $i$ th sensitivity index, and $A_{i}$ is the $i$ th adaptation index.

$$
F=\frac{\left(\sum_{i=0}^{l} W_{\mathrm{ei}} \times E_{i}\right) \times\left(\sum_{i=0}^{m} W_{\mathrm{si}} \times S_{i}\right)}{\sum_{i=0}^{n} W_{\mathrm{ai}} \times A_{i}} .
$$

(2) Research time. With the future development goals of China considered, two stages are chosen as the research period: the 2020s (from 2001 to 2020) and the 2050s (from 2001 to 2050). The vulnerability assessment of Chinese cryospheric changes is performed in $\mathrm{A} 1$ and $\mathrm{B} 1$ scenarios in accordance with IPCC guidelines. The results of the vulnerability assessment in the 2000s (from 1981 to 2000) are also compared with those of the aforementioned two stages.

(3) Selection of indices. Seven indices of exposure, sensitivity, and adaptation are selected for the vulnerability assessment (Table 1). The three indices of exposure are the glacial area fraction, interannual variability of permafrost depth, and interannual variability of surface snow area fraction. The two indices of sensitivity are the interannual variability of surface runoff and the interannual variability of surface temperature. The two indices of adaptation are the interannual variability of vegetation growth and interannual variability of the human development index (HDI) [28]. The calculation unit in this study is county affected by Chinese cryospheric changes.

(4) Weight of indices. The analytic hierarchy process is used in this study to determine the weight of indices [29]. The development of an evaluation matrix helps identify the weight and relative importance of every index. The score of every index is obtained by well-known scientists in the field of cryospheric research. The assessment matrix is constructed through setting the degree of influence of all indices on the basis of a criterion layer in comparison with the superior criterion layer. Eigenvectors are calculated to determine the final weight vectors of the assessment matrix, that is, the weight of indices in the criterion layer. The ratio of random consistency (CR) is also calculated to identify the consistency of the results of the analytic hierarchy process. If $\mathrm{CR}<0.10$, the consistency of the results is acceptable, and the distribution of weighting vectors is logical. All assessment matrices in this study pass the consistency test, and the $\mathrm{CR}<0.10$, which means the consistency of the results is acceptable. Finally, the comprehensive weights of the indices are ranked and calculated, and the final weights of seven vulnerability assessment indices are obtained (Table 2). These seven indices are normalized to restrict the range from 0 to 1 .

Table 1 Index characteristics of Chinese cryospheric changes

\begin{tabular}{llcl}
\hline \multicolumn{1}{c}{ Goal layer } & Criterion layer & First layer of index & Second layer of index \\
\hline & Exposure & Exposure of Chinese cryospheric channges & $\begin{array}{l}\text { Interannual variability of permafrost depth } \\
\text { Vulnerability assessment } \\
\begin{array}{l}\text { of Chinese cryospheric } \\
\text { changes }\end{array}\end{array}$ \\
\cline { 2 - 5 } & Sensitivity & Sensitivity of Chinese cryospheric channges & $\begin{array}{l}\text { Interannual variability of surface runoff } \\
\text { Interannual variability of surface temperature }\end{array}$ \\
\cline { 2 - 5 } & Adaptation & Adaptation of Chinese cryospheric channges & $\begin{array}{l}\text { Interannual variability of vegetation growth } \\
\text { Interannual variability of the HDI }\end{array}$ \\
\hline
\end{tabular}


(5) Climate data. The Community Climate System Model (CCSM3.0) is a coupled climate model with components that represent the atmosphere, ocean, sea ice, and land surface. These components are connected by a flux coupler, which was developed by the National Center for Atmospheric Research [30]. Assessment of the simulation capacity over East Asia of the model, which was included in the IPCC AR4, shows that CCSM3.0 is on the medium level [31]. The simulation results of CCSM3.0 showed a relatively high resolution, so monthly surface air temperature, monthly ground temperature, monthly total precipitation, monthly surface runoff, monthly cloud area fraction, and monthly snow cover fraction are used in this research to calculate the indices.

(6) Calculation of indices. Data from the first glacier inventory are used to calculate the glacial area fraction of every county in the studied area. The shrinkage percentage of temperate glacier, sub-continental glacier, and extremecontinental glacial in the 2020s and 2050s are calculated from the research of Shi and Liu [32]. With these data, the glacial area fraction in the 2020s and 2050s is calculated. Revised Kudryavtsev's permafrost model [33] is used to simulate permafrost depth in the A1 and B1 scenarios from 2001 to 2050 with monthly surface air temperature and monthly total precipitation from CCSM3.0. With these data, the interannual variability of permafrost depth in the 2020s and 2050 s is then calculated. Interannual variability of surface snow area fraction of every county in the studied area in the 2020s and 2050s is calculated with the use of monthly surface snow area fraction data from CCSM3.0 in the A1 and B1 scenarios. Interannual variability of surface runoff of every county in the 2020 s and 2050 s is calculated with the use of surface runoff data from CCSM3.0 in the A1 and B1 scenarios from 2001 to 2050 . Interannual variability of surface temperature is calculated with the use of monthly surface temperature data from CCSM3.0 in the A1 and B1 scenarios of every county in the studied areas in the 2020 s and 2050s. LAI of Chinese terrestrial vegetation from 2001 to 2050 in the A1 and B1 scenarios simulated by BIOME4 [34] with the use of monthly total precipitation and monthly cloud area fraction from CCSM3.0, is used to calculate the interannual variability of vegetation growth of every county in the studied area in the 2020s and 2050s. Because of the lack of data on HDI, the calculation unit of this index is the province, and the value of every county in one province is the same. The HDI in 2020 is 0.84 , which was calculated from the goals on income, health [35] and education (National medium and long term program outline of education reform and development (2010-2020)) in China in 2020 with the definition of HDI. Therefore, the HDI in the studied counties is also assumed to be 0.84 . The interannual variability of HDI in the 2020s is calculated with the use of provincial HDI data in 1999 [36] and HDI data in 2020. The HDI of developed countries in 2000 ranged from 0.90 to 0.94 [37]. The median value of 0.92 is selected as the HDI in the 2050s in the A1 and B1 scenarios. The interannual variability of HDI in the 2050s is calculated from the HDI of 1999 and the 2050s.

The variations in glacial area fraction, interannual variability of permafrost depth, and interannual variability of surface snow area fraction are found to be negative in the A1 and B1 scenarios in the 2020s and 2050s. This result indicates the decreasing trend in glacial area, surface snow area, and permafrost depth, except for the interannual variability of the surface snow area fraction in the 2020s in the A1 scenario. The interannual variability of surface runoff and surface temperature is found to be positive, reflecting an increasing trend in surface runoff and surface temperature in the future, except for the interannual variability of surface runoff in the 2020s in the B1 scenario. The interannual variation of vegetation growth in the A1 and B1 scenarios is respectively found to be positive and negative, indicating a good and an adverse trend in vegetation growth, respectively. The interannual variability of the HDI in the two scenarios is positive, reflecting a strong adaptation capacity in the future (Table 3).

\section{Discussion}

The vulnerability of Chinese cryospheric changes in the 2020s and 2050s was calculated in this study. Cluster analysis identified four thresholds of $0.22,0.36,0.56$, and 0.77 among the vulnerability values in the 2000s, 2020s, and 2050s. Five clusters are formed from the four thresholds, including the slight-vulnerable area (lower than 0.22), light-

Table 2 Weight of the indices of Chinese cryospheric changes

\begin{tabular}{lccc}
\hline & Exposure 0.33 & Sensitivity 0.33 & Adaptation 0.33 \\
\hline Glacial area fraction & 0.1667 & & 0.05556 \\
Interannual variability of permafrost depth & 0.3333 & 0.11109 \\
Interannual variability of surface snow area fraction & 0.5 & 0.75 & 0.16665 \\
Interannual variability of surface runoff & & 0.24998 \\
Interannual variability of surface temperature & & 0.08333 \\
Interannual variability of vegetation growth & & 0.11109 \\
Interannual variability of the HDI & & 0.22221 & 0.6667 \\
\hline
\end{tabular}


Table 3 Characteristics of the vulnerability assessment index of Chinese cryospheric changes

\begin{tabular}{ccccccccc}
\hline Scenario & Time & $\begin{array}{c}\text { Glacial area } \\
\text { fraction change } \\
{[32](\%)}\end{array}$ & $\begin{array}{c}\text { Interannual } \\
\text { variability of the } \\
\text { permafrost depth } \\
\text { (m/a) }\end{array}$ & $\begin{array}{c}\text { Interannual } \\
\text { variability of } \\
\text { surface snow area } \\
\text { fraction }(\%)\end{array}$ & $\begin{array}{c}\text { Interannual } \\
\text { variability } \\
\text { of surface runoff } \\
\left(\mathrm{kg} / \mathrm{m}^{2} \mathrm{a}\right)\end{array}$ & $\begin{array}{c}\text { Interannual } \\
\text { variability } \\
\text { of surface } \\
\text { temperature }\left({ }^{\circ} \mathrm{C} / \mathrm{a}\right)\end{array}$ & $\begin{array}{c}\text { Interannual } \\
\text { variability of } \\
\text { vegetation } \\
\text { growth }\end{array}$ & $\begin{array}{c}\text { Interannual } \\
\text { variability } \\
\text { of the HDI }\end{array}$ \\
\hline \multirow{2}{*}{ A1 } & $2020 \mathrm{~s}$ & -6 to -14 & -0.00326 & 0.07584 & 0.001448 & 0.028160 & 0.57250 & 0.006757 \\
& $2050 \mathrm{~s}$ & -6 to -14 & -0.00815 & -0.04268 & 0.0001446 & 0.015990 & 0.04749 & 0.004480 \\
\hline \multirow{2}{*}{ B1 } & $2020 \mathrm{~s}$ & -13 to -43 & -0.00877 & -0.05865 & -0.0004050 & 0.019360 & -0.00294 & 0.006757 \\
& $2050 \mathrm{~s}$ & -13 to -43 & -0.00810 & -0.01646 & 0.0000099 & 0.006595 & -0.05830 & 0.004480 \\
\hline
\end{tabular}

vulnerable area (from 0.22 to 0.36), medium-vulnerable area (from 0.36 to 0.56 ), strong-vulnerable area (from 0.56 to 0.77 ), and very-strong-vulnerable area ( 0.77 and above). The characteristics of the vulnerability of Chinese cryospheric changes in different periods and scenarios are discussed as follows.

\subsection{Vulnerability analysis of Chinese cryospheric changes in the $2020 \mathrm{~s}$}

In the A1 scenario, the values of vulnerability range from 0.0852 to 0.4762 , with an average of 0.1832 . The vulnerability values in Northeastern China, Northern China, Northwestern China, south of Sichuan Province, Yunnan Province, and Guizhou Province are below 0.22, which can be categorized under the slight-vulnerable area. The vulnerability values in Qinghai Province, southeast of Gansu Province, and north of Sichuan Province range from 0.22 to 0.36 , which can be categorized under the light-vulnerable area. The vulnerability values in Tibet usually exceed 0.36 . Those in the central regions of Tibet range from 0.36 to 0.56 , which can be categorized under the medium-vulnerable area, and those in the south regions of Tibet range from 0.56 to 0.77 , which can be categorized under the strongvulnerable area. In the west and northwest regions of Tibet, the vulnerability values exceed 0.77 , which can be categorized under the very-strong-vulnerable area. In the B1 scenario, the values of vulnerability range from 0.0815 to 0.6128 , with an average of 0.1834 , which is similar to that of the A1 scenario. The distribution of vulnerability in the B1 scenario is similar to that in the A1 scenario, increasing from east to west in China. In Tibet, the strong-vulnerable and very-strong-vulnerable areas in the B1 scenario are larger compared with those in the A1 scenario. The strongvulnerable area is distributed in the central and eastern parts of Tibet, whereas the very-strong-vulnerable area is distributed in the central and northwestern parts of Tibet (Figure 1).

A comparison of the vulnerable areas between the 2000s and 2020s shows that the slight-vulnerable areas of the two scenarios in the $2020 \mathrm{~s}$ are $5.3987 \times 10^{6} \mathrm{~km}^{2}$ and $5.4183 \times 10^{6}$ $\mathrm{km}^{2}$, respectively, which are larger than the $1.8407 \times 10^{6} \mathrm{~km}^{2}$ vulnerable areas in the 2000s. The light-vulnerable and medium-vulnerable areas of the two scenarios are $1.2051 \times 10^{6}$ $\mathrm{km}^{2}$ and $0.9875 \times 10^{6} \mathrm{~km}^{2}$, and $0.4588 \times 10^{6} \mathrm{~km}^{2}$ and 0.1512 $\times 10^{6} \mathrm{~km}^{2}$, respectively, which are less than the vulnerable areas in the 2000s. The strong-vulnerable and very-strongvulnerable areas of the two scenarios are $0.2829 \times 10^{6} \mathrm{~km}^{2}$ and $0.5285 \times 10^{6} \mathrm{~km}^{2}$, and $0.1486 \times 10^{6} \mathrm{~km}^{2}$ and $0.4085 \times 10^{6}$ $\mathrm{km}^{2}$, respectively, which are larger than the vulnerable areas in 2000s. In the two scenarios in the 2020s, the slightvulnerable, strong-vulnerable, and very-strong-vulnerable areas are larger than those in the 2000s, whereas the lightvulnerable, medium-vulnerable areas are less than those in the 2000s.

\subsection{Vulnerability analysis of Chinese cryospheric changes in the $2050 \mathrm{~s}$}

In the A1 scenario, the values of vulnerability range from 0.0346 to 0.3290 , with an average of 0.1048 . In the B1 scenario, the values of vulnerability range from 0.03246 to 0.4138 , with an average of 0.0917 . Similar to those in the 2020 s, the distributions of vulnerability in the 2050s show an increasing trend from east to west in China. The values in a large part of the studied areas, excluding Tibet, are less than 0.22 , which can be categorized under the slight-vulnerable area. In the A1 scenario, the very-strong-vulnerable area disappears, and the strong-vulnerable area is distributed in the northwest of Tibet. In the B1 scenario, the strongvulnerable area is distributed in the middle and western parts of Tibet, whereas the very-strong-vulnerable area is distributed in the northwest part of Tibet (Figure 2).

The slight-vulnerable areas are 6.4214 and $6.4007 \times 10^{6}$ $\mathrm{km}^{2}$ in the A1 and B1 scenarios, respectively, which are higher than those in the 2020s (Table 4). The light-vulnerable areas are 0.4826 and $0.3575 \times 10^{6} \mathrm{~km}^{2}$ for the two scenarios, respectively, which are less than those in the 2020s. The strong-vulnerable and very-strong-vulnerable areas are 0.1182 and $0.116 \times 10^{6} \mathrm{~km}^{2}$, and 0 and $0.116 \times 10^{6} \mathrm{~km}^{2}$ for the two scenarios, respectively, which are less than those in the 2020s. The less vulnerable area increases, and the highly vulnerable area decreases compared with those in the 2020s, which indicates the different characteristics of the two periods.

The comparison of vulnerability among the three periods indicates that the highest vulnerability is in the 2000s with an average value of 0.2644 . Medium vulnerability is in the 2020s with average values of 0.1832 and 0.1834 in the A1 
Table 4 Different vulnerable areas of Chinese cryospheric changes in different scenarios (Unit: $10000 \mathrm{~km}^{2}$ )

\begin{tabular}{|c|c|c|c|c|c|c|}
\hline \multirow{3}{*}{ Scenario } & \multirow{3}{*}{ Time } & \multicolumn{5}{|c|}{ Threshold } \\
\hline & & Slight-vulnerable area & Light-vulnerable area & Medium-vulnerable area & Strong-vulnerable area & Very-strong-vulnerable area \\
\hline & & $<0.22$ & $0.22-0.36$ & $0.36-0.56$ & $0.56-0.77$ & $>0.77$ \\
\hline & $2000 \mathrm{~s}$ & 184.07 & 452.14 & 87.07 & 23.17 & 2.94 \\
\hline \multirow{2}{*}{ A1 } & $2020 \mathrm{~s}$ & 539.87 & 120.51 & 45.88 & 28.29 & 14.86 \\
\hline & $2050 \mathrm{~s}$ & 642.14 & 48.26 & 47.19 & 11.82 & 0.00 \\
\hline \multirow{2}{*}{ B1 } & $2020 \mathrm{~s}$ & 541.83 & 98.75 & 15.12 & 52.85 & 40.85 \\
\hline & $2050 \mathrm{~s}$ & 640.07 & 35.75 & 43.74 & 11.60 & 18.23 \\
\hline
\end{tabular}

and B1 scenarios, respectively. The lowest vulnerability is in the 2050s with average values of 0.1048 and 0.0917 in the A1 and B1 scenarios, respectively. The slight-vulnerable area increases, and the light-vulnerable area decreases from the 2000 s to 2050 s; the medium-vulnerable area increases from the 2000s to 2020s and then decreases from the 2020s to 2050s; and the strong-vulnerable and very-strongvulnerable areas increase from the 2000s to 2020s and then decrease from the 2020s to 2050s (Table 4). These variations in the vulnerable areas of the three periods reflect the complexity brought about by Chinese cryspheric changes.

\subsection{Analysis of the causes of vulnerability variations}

Exposure, sensitivity, and adaptation are examined to analyze the causes of vulnerability variations in Chinese cryospheric changes in different periods and scenarios. The results (Table 5) show that under the $\mathrm{A} 1$ and $\mathrm{B} 1$ scenarios, the values of exposure and sensitivity in the 2020s and 2050 s are lower than those in the 2000s, but the value of adaptation is higher than that in the 2000s. The calculation results with the use of Formula (1) indicate that low exposure and sensitivity and high adaptation result in low vulnerability. Therefore, the value of vulnerability in the 2000s is 0.2644 , which is higher than the value of 0.1832 in the 2020 s and 0.1048 in the 2050 s in the A1 scenario. The 0.2644 value of vulnerability in the 2000 s is also higher than the value of 0.1834 in the 2020 s and 0.0917 in the 2050 s in the B1 scenario. This finding indicates that the vulnerability of Chinese cryospheric changes in the past 20 years is higher than those in the 2020s and 2050s.

The analysis of exposure, sensitivity, and adaptation in the future shows that the value of exposure in the 2020s is higher than that in the 2050s, the value of sensitivity in the
2020 s is lower than that in the 2050s, and the value of adaptation in the 2020s is lower than that in the 2050s. In the A1 scenario, the use of Formula 1 indicates that the value of vulnerability is 0.1832 in the 2020 s, which is higher than the value of 0.1048 in the 2050 s. In the B1 scenario, the values of exposure and sensitivity in the 2020s are higher than those in the 2050s, and the value of adaptation is lower than that in the 2050s. Therefore, the value of vulnerability in the 2020 s is 0.1834 , which is higher than the value of 0.0917 in the 2050s. The vulnerability analysis in the different periods and scenarios shows that with a decrease in the exposure and sensitivity and an increase in adaptation from the 2000 s to 2050 s, the vulnerability decreases slowly.

\section{Summary}

Using the definition of vulnerability provided by the IPCC, this paper conducted a quantitative vulnerability assessment of areas affected by Chinese cryospheric changes. The results show that the values of vulnerability from the 2000s to 2050s decrease slowly in the studied area, which can be attributed to the decrease in exposure and sensitivity to the Chinese cryospheric changes along with a concomitant increase in adaptation. However, the different types of physical science and social science data used in this research could have affected the results and increased the uncertainty involved. Future studies should utilize high-quality data from high-resolution models and ensemble models [38-40] to enhance the accuracy of vulnerability assessment. This preliminary work on the vulnerability assessment of cryospheric changes can give technological and methodological insights into this topic to guide future research. More important, the findings can serve as useful references to

Table 5 Vulnerability assessment of Chinese cryospheric changes in different periods

\begin{tabular}{|c|c|c|c|c|c|c|c|c|}
\hline \multirow{2}{*}{ Time } & \multicolumn{2}{|c|}{ Exposure } & \multicolumn{2}{|c|}{ Sensitivity } & \multicolumn{2}{|c|}{ Adaptation } & \multicolumn{2}{|c|}{ Vulnerability } \\
\hline & $\mathrm{A} 1$ & B1 & $\mathrm{A} 1$ & B1 & $\mathrm{A} 1$ & B1 & $\mathrm{A} 1$ & B1 \\
\hline 2020 s & 0.4640 & 0.4715 & 0.5247 & 0.5016 & 0.1663 & 0.1663 & 0.1832 & 0.1834 \\
\hline $2050 \mathrm{~s}$ & 0.2517 & 0.2492 & 0.5897 & 0.4476 & 0.1736 & 0.1736 & 0.1048 & 0.0917 \\
\hline 2000s & \multicolumn{2}{|c|}{0.4767} & \multicolumn{2}{|c|}{0.6952} & \multicolumn{2}{|c|}{0.1499} & \multicolumn{2}{|c|}{0.2644} \\
\hline
\end{tabular}


formulate appropriate regional social and economic policies for environmental protection and adaptation to climate change.

This work was supported by the National Basic Research Program of China (2007CB411507).

1 IPCC. Climate Change 2007: The Physical Science Basis. Cambridge: Cambridge University Press, 2007. 339-378

2 Qin D H, Qing Y J. Cryospheric changes and their impacts: Present, trends and key issue (in Chinese). Adv Clim Change Res, 2009, 5: 187-195

3 Qin D H, Liu S Y, Liu P. Snow cover distribution, variability, and response to climate change in western China. Clim Change, 2006, 19: 1820-1833

4 Yao T D, Li Z G, Yang W, et al. Glacial distribution and mass balance in the YarlungZangbo River and its influence on lakes. Chin Sci Bull, 2010, 55: 2072-2078

5 Yang M X, Shiklomanov N, Nelson F, et al. Permafrost degradation and its environmental effects on the Tibetan Plateau: A review of recent research. Earth-Sci Rev, 2010, 103: 31-44

6 Guo D L, Wang H J. The significant climate warming in the northern Tibetan Plateau and its possible causes. Int J Clim, 2011, doi: 10.1002/joc. 2388

7 Ma L J, Luo Y, Qin D H. Snow water equivalent over Eurasia in next 50 years projected by CMIP3 models (in Chinese). J Glaciol Geocryol, 2011, 33: 707-720

8 Shi Y, Gao X, Wu J, et al. Changes in snow cover over China in the 21 st century as simulated by a high resolution regional climate model. Environ Res Lett, 2011, 6: 1-8

9 Zhang S L, Tao S Y. Influences of snow cover over the Tibetan Plateau on Asian summer monsoon (in Chinese). Chin J Atmos Sci, 2001, 25: 372-390

10 Liu S Y, Ding Y J, Zhang Y. Impact of the glacial change on water resources in the Tarim river basin (in Chinese). Acta Geogr Sin, 2006, 61: 482-490

11 Wang S L, Lin Q, Zhao L. Permafrost along the Qing-Kang highway (National highway NO. 214 ) (in Chinese). Arid Land Geogr, 1999, 22: 42-49

12 Yuan J Y, Yan S Y, Zhao X F, et al. The relation between permafrost degradation and kobresia meadow change on the southern piedmont of the Tangula range (in Chinese). J Glaciol Geocryol, 1997, 19: 47-51

13 Wang G X, Li Y S, Wu Q B, et al. Impacts of permafrost changes on alpine ecosystem in Qinghai-Tibet Plateau. Sci China Ser D: Earth Sci, 2006, 49: 1156-1169

14 Ren J W, Ye B S, Ding Y J, et al. Initial estimate of the contribution of cryospheric change in China to sea level rise. Chin Sci Bull, 2011, 56: 1661-1664

15 Liu S Y, Sun W X, ShenY P, et al. Glacier changes since the Little Ice Age maximum in the western Qilian Shan, Northwest China, and consequences of glacier runoff for water supply. J Glaciol, 2003, 49: 117-124

16 Yao T D, Wang Y Q, Liu S Y, et al. Recent glacial retreat in high Asia in China and its impact on water resource in Northwest China. Sci China Ser D: Earth Sci, 2004, 47: 1065-1075

17 Ding Y J, Liu S Y, Li J, et al. The retreat of glaciers in response to recent climate warming in western China. Ann Glaciol, 2006, 43: 97-105

18 Zhao L, Ping C L, Yang D Q, et al. Changes of climate and seasonal- ly frozen ground over the past 30 years in Qinghai-Xizang (Tibetan) Plateau, China. Glob Planet Change, 2004, 43: 19-31

19 Wang X, Xie Z C, Liu S Y, et al. Prediction on the variation trend of glacier system in the source region of Tarim River responding to climate change (in Chinese). J Mount Sci, 2006, 24: 641-646

20 Nan Z T, Li S X, Chen G D. Prediction of permafrost distribution on the Qinghai-Tibet Plateau in the nest 50 and 100 years. Sci China Ser D: Earth Sci, 2005, 48: 797-804

21 Guo D L, Wang H J. A projection of permafrost degradation on the Tibetan Plateau during the 21st century. J Geophys Res, 2012, 117, D05106

22 Wang F, Ding Y H. Trend of snow cover fraction in East Asia in 21st century under different scenarios (in Chinese). Plat Meteorol, 2011, 30: $869-877$

23 Wang C H, Wang Z L, Sheng Y P. A prediction of snow cover depth in the northern Xinjiang in the next 50 years (in Chinese). J Glaciol Geocryol, 2010, 32: 1059-1065

24 IPCC. Climate Change 2001: Impacts, Adaptation and Vulnerability. Cambridge: Cambridge University Press, 2001. 89-91

25 Fang Y P, Qin D H, Ding Y J. Scientific issues of ecosystem vulnerability research in the source regions of Yangtze and Yellow Rivers (in Chinese). J Mount Sci, 2009, 27: 140-148

26 Yang J P, Zhang T J. An overview of cryospheric vulnerability and its assessment methods in China (in Chinese). J Glaciol Geocryol, 2010, 32: 1084-1092

27 Deng M Z, Liu S D, Zhang H G. Public perception on the cryosphere changes and selections of adaptation measures in Urümqi River basin (in Chinese). J Glaciol Geocryol, 2011, 33: 1074-1080

28 UNDP. Human Development Report 1990. New York: Oxford University Press, 1990. 9-16

29 Saaty T L. The Analytical Hierarchy Process. New York: McGrawHill Inc, 1980

30 Collins W D, Bitz C M, Blackmon M L. The community climate system model version 3 (CCSM3). J Clim, 2006, 19: 2122-2143

$31 \mathrm{Xu} \mathrm{C} \mathrm{H,} \mathrm{Shen} \mathrm{X} \mathrm{Y,} \mathrm{Xu} \mathrm{Y.} \mathrm{An} \mathrm{analysis} \mathrm{of} \mathrm{climate} \mathrm{change} \mathrm{in} \mathrm{East} \mathrm{Asia}$ by using the IPCC AR4 simulations (in Chinese). Adv Clim Change Res, 2007, 3: 287-292

32 Shi Y F, Liu S Y. Estimation of the response of the glaciers in China to the global warming in the 21st century. Chin Sci Bull, 2000, 45: 668-672

33 Wang C H, Jin S L, Wu Z Y, et al. Evaluation and application of the estimation methods of frozen (thawing) depth over China (in Chinese). Adv Earth Sci, 2009, 24: 132-140

34 Kaplan J O, Bigelow N H, Prentice I C, et al. Climate change and Arctic ecosystems: 2. Modeling, paleodata-model comparisons, and future projections. J Geophys Res, 2003, 108: 8171

35 Chen Z. Chinese strategy and framework of health in 2020. Diabetes Leadership Forum 2009 China. 2009

36 Stockholm Environment Institute. China Human Development Report 2002: Making Green Development A Choice. New York: Oxford University Press, 2002. A3

37 UNDP. Human Development Report 2002-Deepening Democracy in a Fragmented World. New York: Oxford University Press, 2002. 149

38 Gao X J, Shi Y, Giorgi F. A high resolution simulation of climate change over China. Sci China Earth Sci, 2011, 53: 462-472

39 Gao X J, Shi Y, Zhang D F, et al. A high resolution climate change simulation of the 21 st century over China by RegCM3. Chin Sci Bull, 2012, 57: 1188-1195

40 Liu J W, Li B, Zhou T J, et al. The extreme summer precipitation over east China during 1982-2007 simulated by the LASG/IAP regional climate model. Atmos Ocean Sci Lett, 2012, 5: 62-67

Open Access This article is distributed under the terms of the Creative Commons Attribution License which permits any use, distribution, and reproduction in any medium, provided the original author(s) and source are credited. 